www.nature.com/pj

\title{
Hydrophobic cellulose fiber surfaces modified with 2,2,3,3,3-pentafluoropropylmethacrylate (FMA) by vapor-phase-assisted photopolymerization
}

\author{
Yoshito Andou ${ }^{1}$, Jae-Mun Jeong ${ }^{1}$, Masao Kaneko ${ }^{1}$, Haruo Nishida ${ }^{2}$ and Takeshi Endo ${ }^{1}$ \\ We report a simple method to produce a hydrophobic surface created by continual vapor-phase-assisted surface \\ photopolymerization (photo-VASP) of 2,2,3,3,3-pentafluoropropylmethacrylate (FMA), which affords control over the chemical \\ and physical properties of unique substrate surfaces without inducing any morphological changes. The photo-VASP approach \\ was able to modify the surface of cellulose fiber substrates such as a typical, complicated, flexible and soft substrate while \\ maintaining their original properties, imparting superior water repellency without compromising the original tactile nature of the \\ material. The substrate surface was consecutively exposed to the vaporized initiator and monomer FMA under ultraviolet \\ irradiation to start photopolymerization, resulting in selective coating of the irradiated surface with polymer chains. The cellulose \\ fibers coated by the thin polymer layer retained their original tactile nature and demonstrated superior water repellency, with a \\ controlled static contact angle $>130^{\circ}$.
}

Polymer Journal (2010) 42, 519-524; doi:10.1038/pj.2010.31; published online 28 April 2010

Keywords: ESCA/X-ray photoelectron spectroscopy; hydrophobicity; photopolymerization; surfaces; thin-layer coating

\section{INTRODUCTION}

In recent years, a large number of publications have focused on the ability to covalently modify surfaces with polymeric chains to tailor interfacial properties such as repellency, wettability, friction resistance, corrosion resistance and biomedical functions. ${ }^{1-3}$ This modification can be achieved using either 'grafting-to' or 'grafting-from' techniques. Organic solvents are often used to modify substrate surfaces on the basis of conventional liquid processes, with the solvent being completely eliminated from the final products. Organic solvent-minimized or solvent-free processes are ideally suited for sustainable development from the perspective of green chemistry, ${ }^{4}$ as they minimize the consumption of energy and use of chemicals. The liquid pretreatment process may also cause considerable damage to the surface morphology of organic compounds. To control the surface properties without damaging morphology, gentle and thin coating by graft polymerization is required to protect substrates with unique tactile features such as fibers, textile fabrics, fine powders, biological tissues and electronic devices.

One such ideal process is vapor-phase-assisted surface polymerization (VASP), a well-known solvent-minimized or solvent-free method to coat solid surfaces with thin layers. ${ }^{5-9}$ Previously, we reported physically controlled living radical polymerization using free radical initiators by the VASP method, enabling the preparation of block copolymers, ${ }^{10}$ the design of fine patterns, application to surface coatings with a fluorinated polymer ${ }^{11}$ and the development of a homogeneous coating of a fine Fe-powder surface. ${ }^{12}$ In these studies, a small amount of organic solvent was used to precoat initiators on substrate surfaces.

However, pretreatment of substrates with organic agents results in some damage to original properties such as flexibility, softness and the unique tactile nature. This study describes the surface modification of cellulose fiber (cotton fabric) with unique properties by photo-VASP of a fluorinated monomer in a vapor-phase condition without pretreatment with organic agents. The vapor-phase reaction was carried out using two liquid-type photoinitiators: 2-hydroxy2-methylpropiophenone (HMPP) and benzoin isobutyl ether (BIBE). These photoinitiators have definite saturated vapor pressures with appropriate values to vaporize, adsorb and initiate polymerization. The substrate surfaces were consecutively exposed to vaporized initiator and monomer under ultraviolet (UV) irradiation to start photopolymerization. This continual vapor-phase polymerization enables us to not only significantly change the surface properties but also avoid morphological changes associated with liquid processes so that hydrophobicity can be imparted to the fabric surface without any deformation and/or alteration in its original surface morphology.

${ }^{1}$ HENKEL Research Center of Advanced Technology, Molecular Engineering Institute, Kinki University, lizuka, Fukuoka, Japan and ${ }^{2}$ Eco-Town Collaborative R\&D Center for the Environment and Recycling, Kyushu Institute of Technology, Fukuoka, Japan

Correspondence: Professor H Nishida, Eco-Town Collaborative R\&D Center for the Environment and Recycling, Kyushu Institute of Technology, 2-4 Hibikino, Wakamatsu-Ku, Kitakyushu City, Fukuoka, 808-0196, Japan. E-mail: nishida@Isse.kyutech.ac.jp or Professor T Endo, HENKEL Research Center of Advanced Technology, Molecular Engineering Institute, Kinki University, 11-6 Kayanomori, lizuka, Fukuoka, Japan. E-mail: tendo@me-henkel.fuk.kindai.ac.jp

Received 14 January 2010; revised and accepted 23 March 2010; published online 28 April 2010 


\section{EXPERIMENTAL PROCEDURE}

\section{Materials}

Photoinitiators HMPP (97\%) and BIBE (>95\%) were purchased from Aldrich (St Louis, MO, USA) and Tokyo Chemical Industry Co., Ltd (Tokyo, Japan), respectively, and used as received. Free radical initiator 2,2'-azobis(isobutyronitrile) (>99\%) was purchased from Otsuka Chemical Inc (Osaka, Japan) and recrystallized from methanol. Monomer 2,2,3,3,3-pentafluoropropylmethacrylate (FMA) from Daikin Finechemical Laboratory, Ltd (Osaka, Japan) was purified by distillation just before use. Polymerization inhibitor 4-tertbutylpyrocatechol was purchased from Wako Pure Chemical Industries, Ltd (Osaka, Japan) and used as received. All solvents were commercially obtained and used as received. Cotton fabrics (JIS technical standard grade) were purchased from the Japanese Standard Association. Any surface treatment reagents and additives were removed from the cotton fabrics with a Soxhlet apparatus using tetrahydrofuran (THF) as a solvent for $24 \mathrm{~h}$, after which the fabrics were dried for $12 \mathrm{~h}$ at $25^{\circ} \mathrm{C}$.

\section{Measurements}

${ }^{1} \mathrm{H}$ nuclear magnetic resonance ( $\left.{ }^{1} \mathrm{H}-\mathrm{NMR}\right)$ spectra were measured on a 300 MHz AL-300 spectrometer (JEOL Ltd., Tokyo, Japan). Acetone- $d_{6}$ was used as a solvent and chemical shifts were reported as $\delta$ values (p.p.m.) relative to internal tetramethylsilane unless otherwise noted. Fourier transform infrared (FT-IR) spectroscopy was performed using a JASCO FT-IR 460 plus spectrometer (JASCO International Co., Ltd., Tokyo, Japan). Transmission spectra were measured from a $\mathrm{KBr}$ disc coated with polymer samples. Scanning electron microscopy (SEM) was performed on polymer coatings on cotton fabric surfaces with a HITACHI S3000N scanning microscope (Hitachi, Ltd., Tokyo, Japan) at an accelerating voltage of $25.0 \mathrm{kV}$. The microscope was operated at a specimen chamber pressure of $80 \mathrm{~Pa}$ without any electron conductive layer of gold or carbon.

Polymer molecular weights were measured on a TOSOH HLC-8220 gel permeation chromatography (GPC) system (TOSOH Corporation, Tokyo, Japan) with refractive index and UV $(\lambda=254 \mathrm{~nm})$ detectors under the following conditions: TSKgel Super HM-H linear column (TOSOH Corporation, linearity range, $1 \times 10^{3}-8 \times 10^{6}$; molecular weight exclusion limit, $\left.4 \times 10^{8}\right)$, THF (HPLC grade) eluent at a flow rate of $0.6 \mathrm{ml} \mathrm{min}^{-1}$ and a column temperature of $40^{\circ} \mathrm{C}$. The calibration curves for GPC analysis were obtained using polystyrene standards with a low polydispersity $\left(7.70 \times 10^{2}, 2.43 \times 10^{3}\right.$, $3.68 \times 10^{3}, 1.32 \times 10^{4}, 1.87 \times 10^{4}, 2.93 \times 10^{4}, 4.40 \times 10^{4}, 1.14 \times 10^{5}, 2.12 \times 10^{5}$, $3.82 \times 10^{5}, 5.61 \times 10^{5}, 2.00 \times 10^{6}$, Aldrich).

Static contact angle was measured using a Drop Master 500 from Kyowa Interface Science Co., Ltd (Saitama, Japan) on a $2 \mu$ l water droplet at five randomly selected points on the sample surface.

\section{Photo-VASP}

Photo-VASP of FMA was carried out in an $\mathrm{H}$-shaped glass tube reactor with a vacuum stopcock, a quartz plate cap and a glass filter separator (pore size $20-30 \mu \mathrm{m}$ ) at the bridge part (Figure SM-1 in supplementary material). UV irradiation was performed with a point light source from a $320 \mathrm{~W}$ high-pressure mercury lamp MUV-202-U (MORITEX Co., Tokyo, Japan) $(\lambda=280-320 \mathrm{~nm}$ ).

In a typical procedure, the HMPP initiator $(1 \mathrm{ml}, 5.6 \mathrm{mmol})$ was placed at the bottom of the small leg of the H-shaped glass tube. The cotton fabric sample $\left(35 \times 30 \mathrm{~mm}^{2}\right.$; average weight: $\left.103.52 \mathrm{mg}\right)$ was set on a stage at the bottom of the large leg of the H-shaped glass tube. The HMPP in the tube was subjected to three freeze-pump-thaw cycles and then sealed in vacuo. Adsorption of vaporized HMPP on the sample surface was carried out in a saturated vapor of HMPP $\left(6.0 \times 10^{3} \mathrm{~Pa}\right)$ in an oven at $40^{\circ} \mathrm{C}$ for $1 \mathrm{~h}$. After the initiator adsorption, the remaining HMPP was removed using a syringe through the glass stopcock under an Ar atmosphere. Then, a mixture of FMA $(2.0 \mathrm{ml})$ and 4-tert-butylpyrocatechol $(20 \mathrm{mg})$ as an inhibitor was introduced to the bottom of the small leg. The FMA/inhibitor solution in the tube was subjected to three freeze-pump-thaw cycles and then sealed in vacuo. Photopolymerization was carried out in a saturated vapor of FMA $\left(21.5 \times 10^{3} \mathrm{~Pa}\right)$ at $40{ }^{\circ} \mathrm{C}$ under UV irradiation at a distance of $5 \mathrm{~cm}$ from the cotton fabric surface through the quartz plate cap (illumination intensity on the sample surface was $13 \mathrm{~mW} \mathrm{~cm}^{-2}$ $\left(3.2 \times 10^{3}\right.$ lux $)$ through the saturated FMA vapor). After photopolymerization was carried out for the prescribed time, the monomer vapor and adsorbed monomer molecules were eliminated under vacuum for $24 \mathrm{~h}$ at room temperature. The static contact angle between the obtained fabric sample surface and a water droplet was measured, after which the surface coatings were extracted by Soxhlet extraction with THF for $24 \mathrm{~h}$ to analyze the chemical structure of the product by FT-IR, ${ }^{1} \mathrm{H}-\mathrm{NMR}$ and GPC.

To estimate the amount of adsorbed HMPP just before polymerization, the fabric sample was soaked in $25 \mathrm{ml}$ of acetonitrile for $24 \mathrm{~h}$ at room temperature. The amount of adsorbed initiator was estimated from a UV-visible spectrum of the extracted solution on the basis of a calibration curve.

\section{RESULTS AND DISCUSSION}

Continuous vapor-phase polymerization on cotton fabric surfaces Wettability modification of the typical cellulose fiber of cotton fabric was carried out by photo-VASP of FMA with HMPP or BIBE as photoinitiators under UV irradiation. To maintain the original surface morphology of the cotton fabric, photo-VASP was achieved with a vaporized initiator and monomer. Figure 1 shows the expected mechanism of the photo-VASP process step by step. This process begins with step (a), distribution and adsorption of vaporized initiator on the substrate surface, followed by step (b), exchange of the content

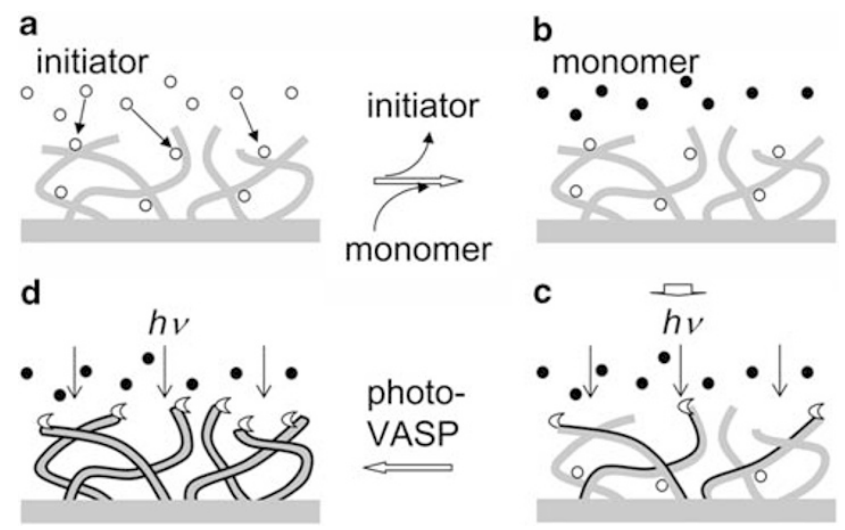

Figure 1 The expected mechanism of the photo-VASP process under UV irradiation: (a) distribution and adsorption of vaporized initiator on the cotton fabric surface; (b) exchange of initiator vapor with FMA vapor; (c) distribution and adsorption of vaporized FMA on the cotton fabric surface; (d) polymerization of adsorbed FMA molecules under UV irradiation.<smiles>CC(C)(O)C(=O)c1ccccc1</smiles><smiles>C[InH2]</smiles><smiles>CC(C)(O)C(=O)c1ccccc1</smiles>

HMPP<smiles>C=C(C)C(=O)OCC(F)(F)F</smiles>

BIBE<smiles>CC(C)COC(C(=O)c1ccccc1)c1cccc(C(=O)[C@H](OCC(C)(C)C)c2ccccc2)c1</smiles>

Scheme 1 Photolysis of HMPP and polymerization of FMA. 
Table 1 Results of VASP of FMA on cotton fabric surfaces under UV irradiation

\begin{tabular}{|c|c|c|c|c|c|c|c|}
\hline Sample & Initiator & Illumination intensity $\left(m W \mathrm{~cm}^{-2}\right)$ & Time $(h)$ & Yield (mg) & $\mathrm{M}_{w}$ & $\mathrm{M}_{w} \mathrm{M}_{n}$ & Contact angle (s.d.) \\
\hline Ref. 1 & & & 0 & - & - & - & Absorbed \\
\hline $1-1$ & & & 1 & 2.7 & 28600 & 2.6 & Absorbed \\
\hline $1-2$ & & & 2 & 3.5 & 43100 & 1.5 & $137.4(3.4)$ \\
\hline $1-3$ & & & 4 & 6.6 & 137000 & 4.9 & $133.7(2.6)$ \\
\hline $1-4$ & HMPP & 13 & 5 & 7.5 & 268000 & 4.9 & $138.3(4.7)$ \\
\hline $1-5$ & & & 6 & 410.8 & 1160000 & 4 & $>130^{\mathrm{b}}$ \\
\hline $1-6^{c}$ & & & 5 & - & - & - & Absorbed \\
\hline $1-7^{d}$ & & & 12 & 2 & 480 & 1.1 & Absorbed \\
\hline Ref. 2 & & 6 & 0 & - & - & - & Absorbed \\
\hline $2-1$ & & 6 & 2 & 0.6 & - & - & 111.1 (18.9) \\
\hline $2-2$ & BIBE & 6 & 4 & 2.1 & 54000 & 2.5 & $133.1(8.6)$ \\
\hline $2-3$ & & 77 & 4 & 36.8 & 610000 & 1.8 & $138.7(5.4)$ \\
\hline
\end{tabular}

Abbreviations: BIBE, benzoin isobutyl ether; FMA, 2,2,3,3,3-pentafluoropropylmethacrylate; HMPP, 2-hydroxy-2-methylpropiophenone; $M_{\mathrm{w}}$, weight-average molecular weight; ref. 1 and 2, reference samples 1 and 2; UV, ultraviolet; VASP, vapor-phase-assisted surface polymerization.

a Measured $5 \mathrm{~s}$ after setting a water droplet of $2 \mu \mathrm{l}$ on the surface at $25^{\circ} \mathrm{C}$. The s.d. value was calculated from values measured at five randomly selected points on the sample surface.

bWater droplet rolled around on substrate surfaces.

${ }^{c}$ Carried out without HMPP.

${ }^{\mathrm{d}}$ Carried out in the dark.

Reaction conditions: initiator adsorption, at $40^{\circ} \mathrm{C}$ for $1 \mathrm{~h}(\mathrm{HMPP})$, at $80^{\circ} \mathrm{C}$ for $1 \mathrm{~h}(\mathrm{BIBE})$; polymerization of FMA, at $40^{\circ} \mathrm{C}$ under UV irradiation.

in the vapor phase from initiator to monomer molecules. In step (c), the photolysis of the absorbed initiator occurs under UV irradiation to generate active species (Scheme 1), and then in step (d), the generated active species induce the surface polymerization of monomers from the vapor phase.

The amount of adsorbed initiators on the fabric surface after step (a) for $1 \mathrm{~h}$ at $40{ }^{\circ} \mathrm{C}$ was estimated from the UV spectra of solutions extracted by acetonitrile, resulting in a 0.97 (HMPP) and 0.0089 (BIBE) $\mu$ mol per fabric sample. Photo-VASP of FMA (steps (c)-(d)) was carried out at $40^{\circ} \mathrm{C}$ under UV irradiation at various reaction times and illumination intensities in the range of $6-77 \mathrm{~mW} \mathrm{~cm}^{-2}$ (Table 1). Table 1 reports the polymerization results. In the cases using HMPP, the total sample weight increased with time, indicating polymer accumulation on the sample surface. GPC analysis of the extracted products showed a steady increase in molecular weight with time, resulting in a weight-average molecular weight $\left(M_{\mathrm{w}}\right)>1000000$ after $6 \mathrm{~h}$ of reaction. On the other hand, no accumulation was obtained without HMPP (sample 1-6). In the absence of UV irradiation, a small amount of oligomeric product $\left(2.0 \mathrm{mg}, M_{\mathrm{w}}=480\right)$ was obtained after a long period (12 h) (sample 1-7). These results clearly indicate that PFMA production on the fabric surface was achieved only in the presence of both initiator and UV irradiation. Photo-VASP with BIBE was also carried out under various luminescent intensities for various irradiation periods, resulting in a similar accumulation of PFMA on the fabric surface and demonstrating that irradiation intensity has a considerable effect on both the yield and the molecular weight of the accumulated polymer.

The products accumulated on the substrate surfaces were characterized by FT-IR, ${ }^{1} \mathrm{H}-\mathrm{NMR}$ and GPC and compared with PFMA $\left(M_{\mathrm{n}}=29000, M_{\mathrm{w}}=49000\right)$ prepared in bulk polymerization with 2,2'azobis(isobutyronitrile) at $80^{\circ} \mathrm{C}$ for $1 \mathrm{~h}$. VASP products were extracted overnight with THF using a Soxhlet apparatus at reflux temperature to remove free polymers that have accumulated on the surfaces. After extraction, ${ }^{1} \mathrm{H}-\mathrm{NMR}$ and FT-IR spectra of the polymer extracted from samples 1-3 showed the same profiles as the spectra of PFMA obtained by bulk polymerization (see Figures SM-2 and SM-3 in Supplementary materials). For example, a broad singlet at 4.65 p.p.m. assigned to $-\mathrm{COOCH}_{2} \mathrm{C}_{2} \mathrm{~F}_{5}$ in the ${ }^{1} \mathrm{H}$-NMR spectrum and characteristic FT-IR peaks at $1756 \mathrm{~cm}^{-1}$ assigned to $v_{\mathrm{C}=\mathrm{O} \text {,ester }}$ as well as
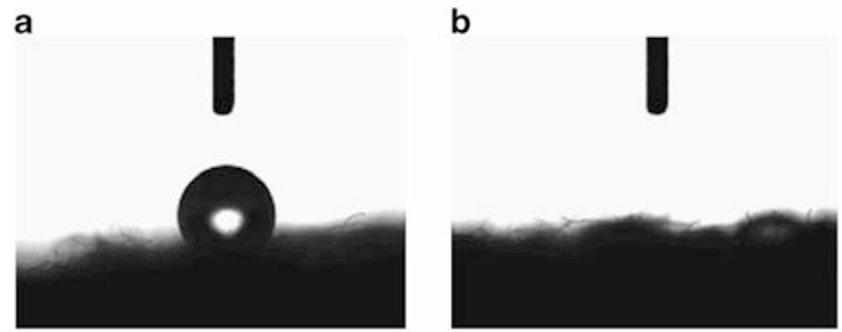

Figure 2 Microscopic images of water droplets (a) on a photo-VASP-treated surface with FMA/HMPP under UV irradiation and (b) on the opposing surface without UV irradiation.

1170 and $1218 \mathrm{~cm}^{-1}$ assigned to $v_{\mathrm{C}-\mathrm{F}}{ }^{13}$ were all similar. These analytical results agree with previously reported values of PFMA. ${ }^{14}$ The molecular weight of the extracted polymers ranged from 28600 to 1160000 in $M_{\mathrm{w}}$, with large polydispersity values of 2.6-4.9, consistent with the peculiar structural property of photo-VASP products as previously reported. ${ }^{10,12,15}$

As listed in Table 1, PFMA production with HMPP gradually increased from 2.7 to $7.5 \mathrm{mg}$ over a period of up to $5 \mathrm{~h}$. Over $5 \mathrm{~h}$, a significant increase in polymer accumulation $(410.8 \mathrm{mg})$ was observed as shown in samples $1-5$ (reaction time $6 \mathrm{~h}$ ), with an extreme increase in molecular weight. This suggests that the propagation reaction was greatly accelerated once the reaction time exceeded $5 \mathrm{~h}$. A similar phenomenon was observed in a previous study of VASP. ${ }^{10}$ Thus, this acceleration must be caused by factors such as an increase in the adsorption and absorption area of monomer molecules and the suppression of termination reactions caused by the isolation of active chain ends on the top surface of deposits, as reported previously. ${ }^{11}$

Multimodal profiles with wide polydispersity values are typical profiles of the photo-VASP products obtained in this study. In spite of the multimodal profiles, the molecular weight tended to increase monotonously with the reaction time and polymer yield, demonstrating continuous propagation characteristics in photo-VASP. ${ }^{10}$

\section{Properties of modified surfaces}

Cotton fabric is typically wettable, showing a smooth absorption of water droplets on the surface. Surface deposition of PFMA is expected 


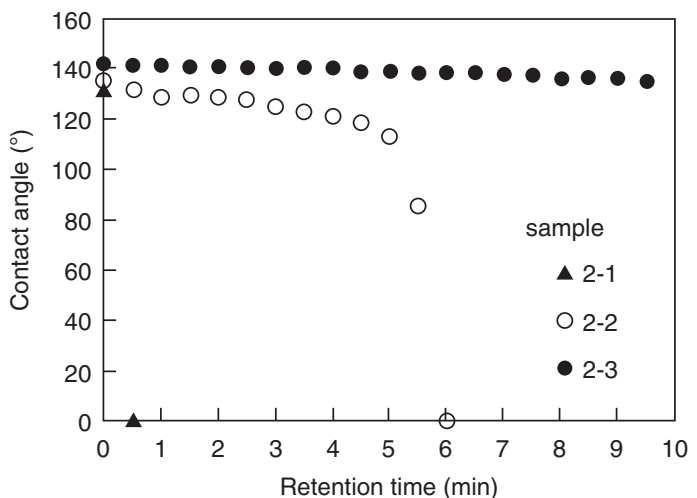

Figure 3 Changes in water droplet contact angles on cotton fabric surfaces treated by photo-VASP of FMA.

to impart water repellency because of the low surface free energy of PFMA. ${ }^{16}$ Moreover, surface roughness has a remarkable effect on the apparent hydrophobicity because of the lotus effect. ${ }^{17}$ Figure 2 shows a water droplet on the treated surface and on the opposing surface of cotton fabrics after photo-VASP of FMA. The photo-VASP-treated surface exhibits superior water repellency, as demonstrated by the round-shaped water droplet sitting on the surface (Figure 2a). On the other hand, the reverse surface, which did not undergo UV irradiation, retains the normal hydrophilic property of cotton fabrics, resulting in rapid absorption of the water droplet (Figure 2b). These results indicate that the UV-irradiated surface was selectively changed into a superior hydrophobic surface by photo-VASP while retaining its original surface morphology.

Changes in the surface wettability of cotton fabrics were assessed by measuring the static contact angle of a water droplet on the surface. The results are presented in Table 1. Untreated cotton fabrics easily absorbed water droplets because of their naturally superior hydrophilic property (contact angle $\left.\approx 00^{\circ}\right) .{ }^{15}$ No change in this property was observed after the adsorption of the initiator, with the same rapid absorption of water droplets (reference samples 1 and 2 in Table 1). After photo-VASP of FMA, the hydrophilic property of the surface became hydrophobic with discontinuous dependence on the accumulated amount, so that the water droplet was held on the surface and maintained its round shape (contact angle $>130^{\circ}$ ) (samples $1-2$ to $1-$ 5 and $2-2$ to $2-3$ in Table 1 ).

The relationship between PFMA accumulation and water repellency was illustrated in Figure 3 using three typical examples. In the case of sample 2-1 (accumulation: $0.6 \mathrm{mg}, 57 \mu \mathrm{g} \mathrm{cm}^{-2}$ ), a water droplet was rapidly absorbed into the fabric body within $30 \mathrm{~s}$, showing a sudden drop in the contact angle value. On the surface of sample $2-2(2.1 \mathrm{mg}$, $200 \mu \mathrm{g} \mathrm{cm}^{-2}$ ), a water droplet maintained its round shape for 5$10 \mathrm{~min}$, but thereafter was gradually absorbed into the fabric because of the combined effects of capillary action and the internal native fabric properties. Sample $1-2\left(3.5 \mathrm{mg}, 333 \mu \mathrm{g} \mathrm{cm}^{-2}\right)$ displayed the same gradual absorption behavior. Sample $2-3$ (36.8 mg, $3500 \mu \mathrm{g} \mathrm{cm}^{-2}$ ) in Figure 3 had sufficient hydrophobicity to allow the water droplet to retain its roundness on the surface for over $10 \mathrm{~min}$. Similar results were obtained on the surfaces of samples 1-3 (6.6 mg, $629 \mu \mathrm{g} \mathrm{cm}^{-2}$ ) and $1-4\left(7.5 \mathrm{mg}, 714 \mu \mathrm{g} \mathrm{cm}^{-2}\right)$. These results suggest that there is a critical accumulation value in the range of 333$629 \mu \mathrm{g} \mathrm{cm}^{-2}$, at which the repelling property changes discontinuously.

In spite of displaying such a superior hydrophobic character, PFMA-coated fabrics retained their original tactile nature. However, in the case of sample $1-5$, the original tactile nature was lost and a

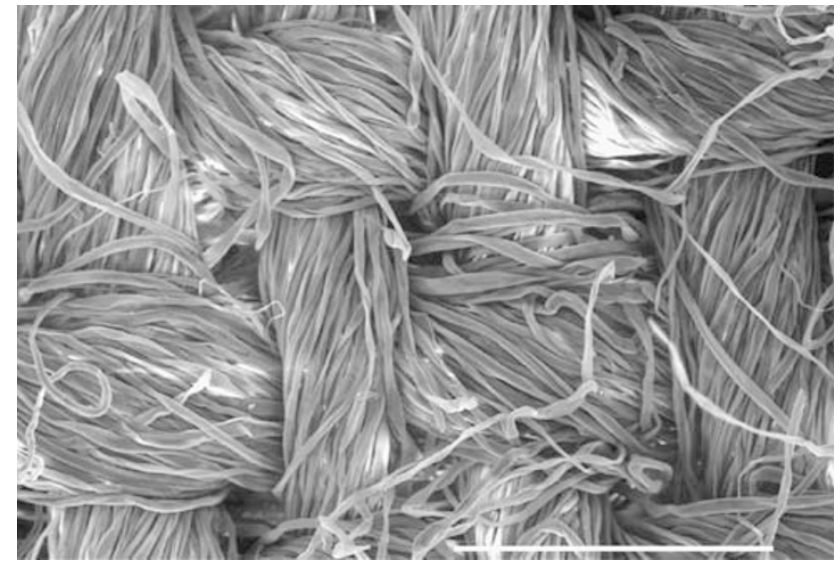

Figure 4 SEM image of a cotton fabric surface treated by photo-VASP of FMA. Sample 1-4. Scale bar: $500 \mu \mathrm{m}$.

hard solid-like surface was produced as a result of excess accumulation of PFMA ( $410.8 \mathrm{mg}, 39 \mathrm{mg} \mathrm{cm}^{-2}$ ) on the surface. This indicates that the photo-VASP method successfully achieved homogeneous accumulation of polymer on cellulose fiber in a short period of time.

Similar to the native cotton fabric, reference samples 1-6 and 1-7 showed rapid absorption of water droplets because of the absence of initiator or the failure to accumulate sufficient polymer. Therefore, the superior water repellency and the preserved tactile nature were achieved by a polymer accumulation layer that was thicker than $333 \mu \mathrm{g} \mathrm{cm}^{-2}$. This clearly indicates that the hydrophobic property is based on the surface layer.

\section{Changes in surface morphology after photo-VASP}

Changes in the morphology of the cotton fabric surface after photoVASP of FMA were examined by SEM observation. Figure 4 shows a typical SEM image of the treated surface (sample 1-4) after photoVASP. No change in the morphology of the treated surface was observed, indicating that the original fabric surface has been preserved. This is because sufficient polymer accumulation $\left(714 \mu \mathrm{g} \mathrm{cm}^{-2}\right)$ for water repellency was achieved in a homogeneous thin polymer layer. On the other hand, a large accumulation of PFMA on the surface (sample 1-5, $39 \mathrm{mg} \mathrm{cm}^{-2}$ ) caused the original surface morphology to be lost as a large amount of polymer covered the fine structure of the fabric surface (see Figure SM-4 in Supplementary materials).

The cotton fabric substrate (macroscopic dimensions of $35 \times 30 \mathrm{~mm}^{2}$ ) must have a huge actual surface area. Considering the weight ratio of accumulated polymer to substrate (average weight: $103.5 \mathrm{mg}$ ), more than $3.5 \mathrm{mg}$ per sample $\left(333 \mu \mathrm{g} \mathrm{cm}^{-2}\right)$ is required to impart superior water repellency. The accumulated polymers may include free and/or combined chains. To determine the distribution of free/combined PFMA components, the accumulated free polymer was dissolved by THF as a good solvent. Figure 5 shows SEM images before and after the extraction of free polymer from sample 2-3 (accumulation: $36.8 \mathrm{mg}, 3500 \mu \mathrm{g} \mathrm{cm}^{-2}$ ). After extraction, the sample weight became nearly equal to the original substrate weight, signifying that almost all of the accumulated polymer chains on the surface were in the form of free deposits. Figure 5 clearly shows that the polymer deposits covered the fiber surfaces after photo-VASP (Figure 5a), whereas the extracted fiber surfaces recovered their original smooth morphology (Figure 5b). The analysis of SEM images indicated that the PFMA coatings had a thickness of around $2-3 \mu \mathrm{m}$ even when $3500 \mu \mathrm{g} \mathrm{cm}^{-2}$ had accumulated. 

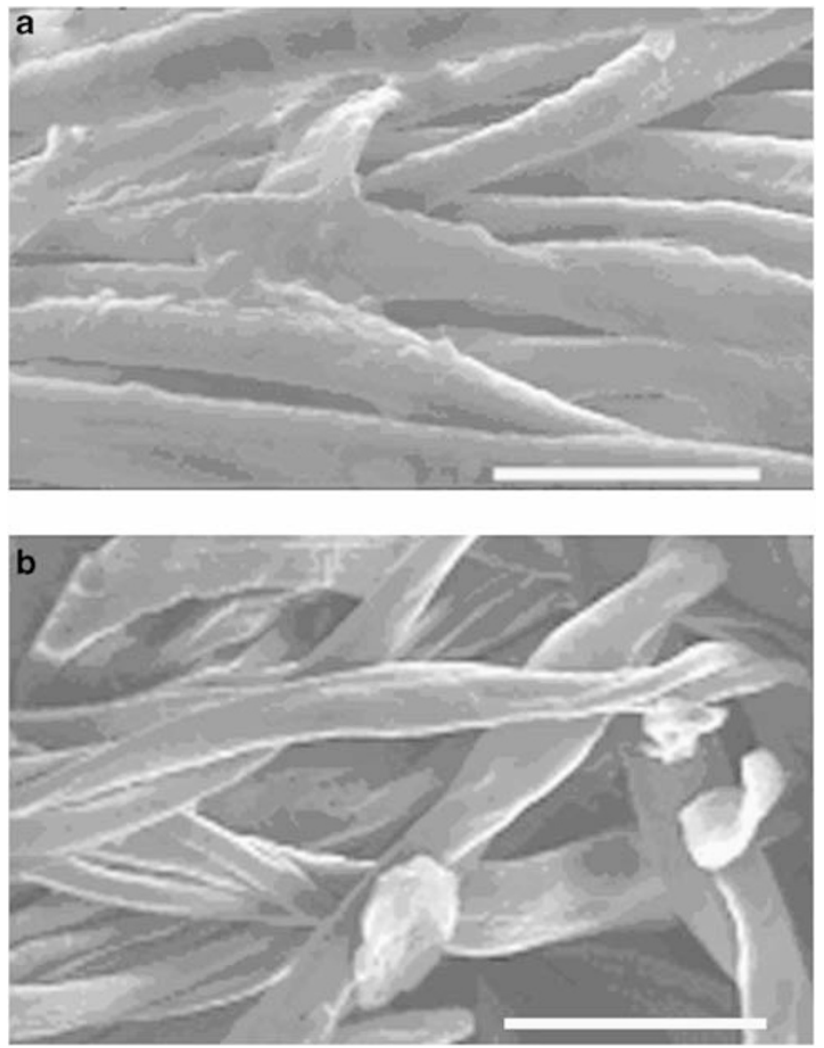

Figure 5 SEM images of the cotton fabric surface of sample 2-3 (a) before and (b) after extraction of free polymer by THF. Scale bar: $50 \mu \mathrm{m}$.

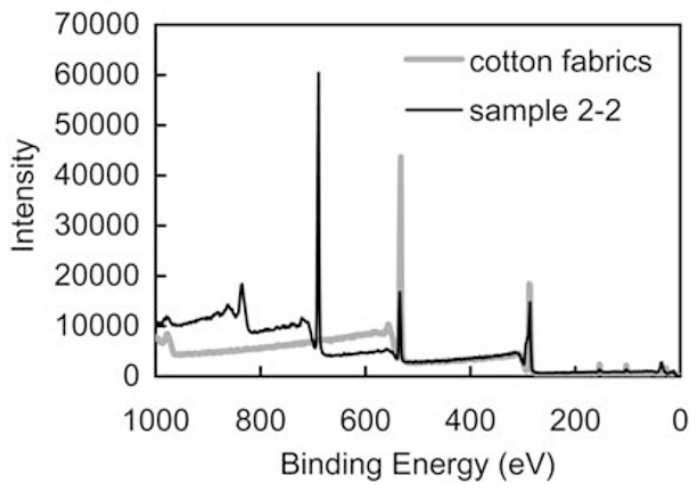

Figure 6 XPS wide-scan spectrum of sample 2-2 and of original cotton fabric surfaces.

Interestingly, the extracted cotton surface also showed a high static contact angle value with a water droplet of $138.3^{\circ}\left(\right.$ s.d. $\left.=5.3^{\circ}\right)$. This retention of hydrophobicity even after the extraction of free polymer chains indicates that the grafting of PFMA chains from/on the cotton surface occurred through chain-transfer reactions such as hydrogen abstraction by generated and growing chain-end radicals during photo-VASP. A similar phenomenon was reported by Ogiwara et al., ${ }^{18}$ wherein graft copolymerization of methyl methacrylate occurred on cellulose substrates under UV irradiation. The grafting is affected by the extent of photoinitiator adsorption, the intensity of irradiation and the rate at which accumulated polymer chains cover the surface. Moreover, this finding suggests that superior water
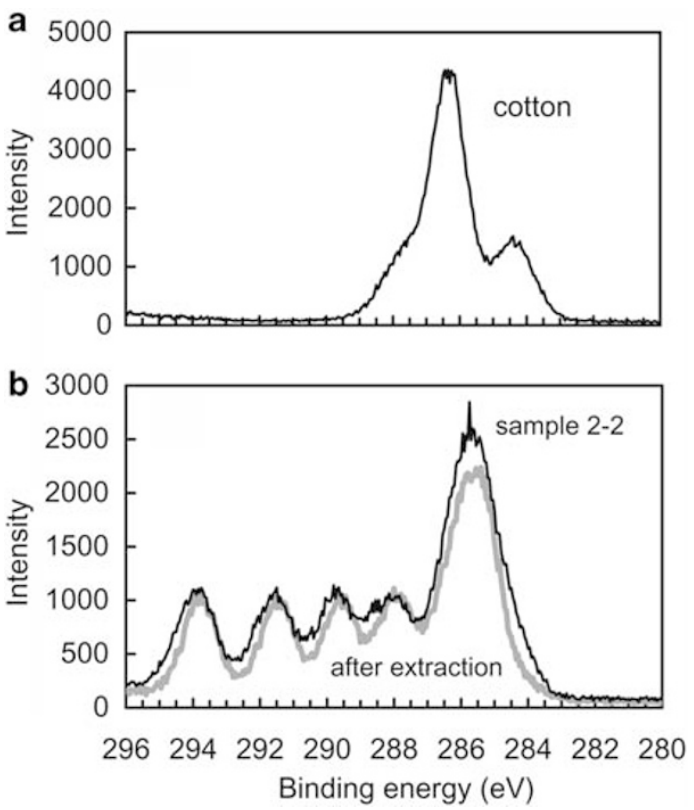

Figure 7 XPS C1s core-level spectra of (a) original cotton and (b) photo-VASPtreated sample 2-2 surfaces. Extraction: Soxhlet extraction for $24 \mathrm{~h}$ with THF.

repellency can be achieved by coating the substrate surface with an extremely thin layer.

\section{XPS analysis of photo-VASP-treated fabric surfaces}

To confirm PFMA coverage and grafting on the substrate by photoVASP, the chemical composition of the surface layer was characterized by X-ray photoelectron spectroscopy (XPS). Figure 6 shows the widescan XPS spectrum of sample 2-2 and of the original cotton surfaces. The spectrum of sample 2-2 contains a clear F1s signal with a binding energy (BE) of $690 \mathrm{eV}$ attributed to the $\mathrm{F}$ atoms in PFMA. No F1s signal was observed in the spectrum of the original cotton surface.

Figure 7 shows C1s core-level spectra of original cotton and sample 2-2 surfaces before and after extraction by a Soxhlet apparatus using $\mathrm{THF}$ as the solvent. The C1s signals of the original cotton in Figure $7 \mathrm{a}$ consist of a main component with a $\mathrm{BE}$ of $286.25 \mathrm{eV}$ and a minor component with a $\mathrm{BE}$ of $284.25 \mathrm{eV}$, attributable to component carbons of cellulose. ${ }^{19}$ In Figure $7 \mathrm{~b}$, the C1s signals were dominated by component carbons of PFMA. Higher $\mathrm{BE}$ signals in the range of 287-295 eV indicate the presence of $\mathrm{CF}_{3}, \mathrm{CF}_{2}, \mathrm{C}=\mathrm{O}$ and $\mathrm{C}-\mathrm{O}$ species on the photo-VASP-treated surface. A nearly equivalent XPS profile was obtained from the extracted sample 2-2 surface. This result clearly demonstrates that PFMA chains exist as a grafted ultrathin layer on cellulose fiber. ${ }^{20}$

\section{CONCLUSION}

Photo-VASP performed continuously in the vapor phase was demonstrated through the successful alteration of the surface properties of cellulose fiber while maintaining the original surface morphology. Cellulose fabrics were consecutively exposed to vaporized initiator and FMA monomer under UV irradiation to start photopolymerization, resulting in the selective accumulation of PFMA on the irradiated surface. Both the radical initiator and UV irradiation were essential for accumulation by photo-VASP. The treated substrate surfaces showed superior water repellency with a static contact angle value $>130^{\circ}$. In spite of the addition of the polymer coating to impart superior water repellency, the cellulose fiber retained its original tactile nature when 
the deposition was controlled within a proper range of polymer accumulation. These results suggest that this method could be used to control the properties of many complicated, artificial and/or natural polymer surfaces by photo-VASP using various monomers and initiators. Thin-layer coating by photo-VASP may be used to construct a variety of surfaces with new functionalities without compromising delicate surface morphologies.

\section{ACKNOWLEDGEMENTS}

This work was performed under the sponsorship of Henkel KGA (Germany).

1 Nakayama, Y. \& Matsuda, T. Surface macromolecular microarchitecture design: biocompatible surfaces via photo-block-graft-copolymerization using $\mathrm{N}, \mathrm{N}$-diethyldithiocarbamate. Langmuir 15, 5560-5566 (1999).

2 Jung, D.- H., Park, I.- J., Choi, Y.- K., Lee, S.- B., Park, H.- S. \& Rühe, J. Perfluorinated polymer monolayers on porous silica for materials with super liquid repellent properties. Langmuir 18, 6133-6139 (2002).

3 Anastasiadis, S. H., Retsos, H., Pispas, S., Hadjichristidis, N. \& Neophytides, S. Smart polymer surfaces. Macromolecules 36, 1994-1999 (2003).

4 Smaglik, P. 'Quiet revolution' in chemistry could revive public and private sectors. Nature 406, 807-808 (2000).

5 Chan, K. \& Gleason, K. K. Initiated chemical vapor deposition of linear and cross-linked poly(2-hydroxyethyl methacrylate) for use as thin-film hydrogels. Langmuir 21, 89308939 (2005).

6 Chan, K. \& Gleason, K. K. Photoinitiated chemical vapor deposition of polymeric thin films using a volatile photoinitiator. Langmuir 21, 11773-11779 (2005).

7 Morita, H. \& Sadakiyo, T. Laser-induced polymeric film formation from gaseous methyl acrylate. J. Photochem. Photobiol. A: Chem. 87, 163-167 (1995).
8 Ma, M ., Mao, Y., Gupta, M ., Gleason, K.K. \& Rutledge, G. C. Superhydrophobic Fabrics Produced by Electrospinning and Chemical Vapor Deposition. Macromolecules 38, 9742-9748 (2005).

9 Lau, K. S., Mao, Y., Pryce Lewis, H. G., Murthy, S. K., Olsen, B. D., Loo, L. S. \& Gleason, K. K. Polymeric nanocoatings by hot-wire chemical vapor deposition (HWCVD). Thin Solid Films 501, 211-215 (2006).

10 Yasutake, M., Hiki, S., Andou, Y., Nishida, H. \& Endo, T. Physically controlled radical polymerization of vaporized vinyl monomers on surfaces. Synthesis of block copolymers of methyl methacrylate and styrene with a conventional free radical initiator. Macromolecules 36, 5974-5981 (2003).

11 Yasutake, M., Andou, Y., Hiki, S., Nishida, H. \& Endo, T. Physically controlled, free radical polymerization of vaporized fluoromonomer on solid surfaces. J. Polym. Sci., Part: A Polym. Chem. 42, 2621-2630 (2004).

12 Andou, Y., Yasutake, M., Jeong, J. M., Nishida, H. \& Endo, T. Gas-phase assisted surface polymerization of vinyl monomers with Fe-based initiating systems. Macromol. Chem. Phys. 206, 1778-1783 (2005).

13 Yasutake, M., Andou, Y., Hiki, S., Nishida, H. \& Endo, T. Controlled radical polymerization of vaporized vinyl monomers on solid surfaces under UV irradiation. Macromol. Chem. Phys. 205, 492-499 (2004).

14 Guo, X., Weiss, A. \& Ballauff, M. Synthesis of spherical polyelectrolyte brushes by photoemulsion polymerization. Macromolecules 32, 6043-6046 (1999).

15 Carlmark, A. \& Malmström, E. Atom transfer radical polymerization from cellulose fibers at ambient temperature. J. Am. Chem. Soc. 124, 900-901 (2002).

16 Park, I. J., Lee, S.- B C. \& Choi, K. Atom transfer radical polymerization from cellulose fibers at ambient temperature. Macromolecules 31, 7555-7558 (1998).

17 Jung, D.- H. I., Park, J., Choi, Y. K., Lee, S.- B., Park, H.S. \& Ruhe, J. Perfluorinated polymer monolayers on porous silica for materials with super liquid repellent properties. Langmuir 18, 6133-6139 (2002).

18 Ogiwara, Y., Kubota, H. \& Murata, Y. Relationship between photo-induced scission of cellulose chains and graft copolymerization. J. Appl. Polym. Sci. 18, 3455-3462 (1974).

19 NIST X-ray Photoelectron Spectroscopy Database, http://srdata.nist.gov/xps/Bind_e_ spec_query.asp.

20 Beamson, G. \& Briggs, D. High resolution XPS of organic polymers: the Scienta ESCA300 Database (John Wiley \& Sons, Chichester, UK, 1992).

Supplementary Information accompanies the paper on Polymer Journal website (http://www.nature.com/pj) 